\title{
Relationship Between Clinical Control, Respiratory Symptoms and Quality of Life for Patients with COPD
}

This article was published in the following Dove Press journal:

International Journal of Chronic Obstructive Pulmonary Disease

Bernardino Alcazar-Navarrete, (iD) 1,2 Antonia Fuster, ${ }^{3}$ Patricia García Sidro, ${ }^{4}$ Juan Luis García Rivero, ${ }^{5}$ Beatriz Abascal-Bolado, ${ }^{6}$ Abel PallarésSanmartín, (iD) Eduardo Márquez, ${ }^{2,8}$ Agustin Valido-Morales, (iD) 9 Ana Boldova Loscertales, (iD) ${ }^{10}$ Francisco Javier Callejas-Gonzalez, (D) " Marta Palop, ${ }^{12}$ Juan Antonio Riesco, (D) ${ }^{2,13}$ Rafael Golpe, ${ }^{14}$ Juan Jose SolerCataluña, ${ }^{2,15}$ Marc Miravitlles (iD) 2,16

'AIG De Medicina. Hospital De Alta Resolución De Loja. Agencia Sanitaria Hospital De Poniente, Loja, Granada, Spain; ${ }^{2}$ CIBERES. Instituto De Salud Carlos III, Madrid, Spain; ${ }^{3}$ Servicio De Neumología. Hospital Universitario De Son Llatzer, Palma De Mallorca, Spain; ${ }^{4}$ Servicio De Neumología. Hospital De La Plana,

Castellón, Spain; ${ }^{5}$ Servicio De Neumología. Hospital De Laredo, Laredo, Spain; ${ }^{6}$ Servicio De Neumología. Hospital Universitario Marqués De Valdecilla, Santander, Spain ${ }^{7}$ Servicio De Neumología. Hospital Universitario Alvaro Cunqueiro, Vigo, Spain; ${ }^{8}$ Unidad Médico-Quirúrgica De Enfermedades Respiratorias. Hospital Virgen Del Rocío, Sevilla, Spain; ' UGC De Neumología. HU Virgen Macarena, Sevilla, Spain; ${ }^{10}$ Servicio De Neumología. Hospital Royo Villanova, Zaragoza, Spain; "'Servicio De Neumología. Complejo Hospitalario Universitario De Albacete, Albacete, Spain;

${ }^{12}$ Servicio De Neumología. Hospital De Sagunto, Sagunto, Spain; ${ }^{13}$ Servicio De Neumología. Hospital San Pedro De Alcántara, Cáceres, Spain; ${ }^{14}$ Servicio De Neumología. Hospital Universitario Lucus Augusti, Lugo, Spain; ${ }^{15}$ Servicio De Neumología. Hospital Arnau De VillanovaLliria, Valencia, Spain; ${ }^{16}$ Servicio De Neumología. Hospital Universitari Vall De Hebron/Vall d'Hebron Institut De Recerca, Barcelona, Spain

Correspondence: Bernardino AlcazarNavarrete

Hospital De Alta Resolución De Loja. Agencia Sanitaria Hospital De Poniente. Avda Tierno Galván s/n, Loja 18300, Granada, Spain

Email balcazar@telefonica.net
Background: The concept of clinical control has been proposed as an instrument for evaluating patients with COPD. However, the possible association between clinical control, reduced symptom severity and HRQoL has yet to be confirmed.

Methods: This multicentre, prospective and observational study was carried out in 15 pulmonology clinics in Spain. The patients were followed up for six months, with a baseline visit (V0), followed by visits at three months (V1) and six months (V2). Clinical control was determined at V1, with the application of both clinical criteria and the COPD assessment test (CAT). All patients reported their symptoms by a validated symptom diary (E-RS) using a portable device, and their HRQoL was assessed using the EQ5D questionnaire. The relationship between clinical control and E-RS and HRQoL during follow-up was assessed with $t$-test.

Results: A total of 126 patients were screened. After application of the inclusion/exclusion criteria, 93 were finally included (mean age $66 \pm 8$ years, $84.9 \%$ male), with a mean $\mathrm{FEV}_{1}$ predicted of $49.8 \% \pm 16.5 \%$. Of these patients, $44(47.3 \%)$ achieved clinical control at V1, according to CAT criteria, and 50 (53.8\%), according to clinical criteria. The E-RS scores differed between controlled and uncontrolled patients at all time points, both according to CAT (mean differences of $-4.6,-5.6$ and -6.2 units at V0, V1 and V2, respectively, $\mathrm{p}<0.005$ for all comparisons) and to clinical criteria (mean differences of $-3.3,-5-6$ and -4.99 units, respectively, $\mathrm{p}<0.005$ for all comparisons). The controlled patients also presented a significantly better HRQoL, measured by the EQ5D questionnaire (mean difference 0.13 and 0.10 at V2 by CAT or clinical criteria, respectively, $\mathrm{p}<0.05$ ).

Conclusion: Clinical control in patients with COPD, whether measured by CAT or by clinical criteria, is associated with a lower symptom load and a better HRQoL.

Keywords: control, symptoms, quality of life, impact, COPD

\section{Background}

COPD (Chronic Obstructive Pulmonary Disease) is a chronic respiratory disease, with a prevalence above $10 \%$ in Spain, ${ }^{1}$ that mainly affects older age groups, provoking long-term disability and placing a significant burden on health systems. $^{2}$ One of the major limitations associated with COPD is dyspnea, which significantly worsens patients' health-related quality of life (HRQoL), even among those who suffer a relatively mild limitation of airflow. ${ }^{3,4}$ Furthermore, dyspnea is a prognostic factor per se in COPD, and is associated with a greater mortality. ${ }^{5}$ In addition to this predominant symptom, others such as cough and expectoration are cited by patients as factors that limit their daily activities. ${ }^{6,7}$ These symptoms can be evaluated via clinical questions or using validated questionnaires or by means of 
self-completed symptom diaries, such as the EXACT Respiratory Symptoms (E-RS $\left.{ }^{\circledR}\right)$ questionnaire. ${ }^{8}$ The E-RS is a patient-reported outcome (PRO) which has been approved as a validated tool for assessing respiratory symptoms during clinical trials and observational studies in a daily basis.

The concept of clinical control in COPD has been proposed as a dynamic means of detecting changes in patients' clinical situation that may be related to prognostic implications. ${ }^{9,10}$ Clinical control is defined as the longterm persistence of a situation of low clinical impact; in other words, it is composed of a transversal dimension (the clinical impact) together with a longitudinal one (clinical stability), determined by exacerbations or worsening over time. Studies have shown that clinical control can be achieved by a high proportion of patients, even among those with greater airflow limitation, ${ }^{11-14}$ although control status may vary over time, ${ }^{15}$ and that patients whose condition is uncontrolled are at greater risk of unfavourable outcomes. ${ }^{16}$ However, in the absence of previous research in this area, it is unclear whether patients who are clinically controlled have less symptom burden and a better HRQoL than those who are not.

In view of these considerations, our study aim was to determine whether patients who present clinical control have fewer respiratory symptoms and better HRQoL (based on a validated symptom diary such as the E-RS) than those whose condition was uncontrolled.

\section{Methods}

\section{Study Design}

This observational, prospective, multicentre study was conducted in outpatient pulmonology consultations in Spain, with a six-month follow-up. Centers were selected based on geographical distribution and similar care across different healthcare systems. Patients were included consecutively. Three visits were scheduled (V0, V1 and V2). Study design and visits procedures are available on table S1.

\section{Study Population}

The study population consisted of adult patients aged $>40$ years with a diagnosis of COPD, according to national and international recommendations. ${ }^{17,18}$ All were smokers or ex-smokers with an accumulated tobacco consumption of at least 10 pack-years and with a postbronchodilator forced expiratory volume in 1 second $\left(\mathrm{FEV}_{1}\right)$ /forced vital capacity (FVC) $<0.7{ }^{18}$ These patients had been followed for at least three months before $\mathrm{V} 0$ and were able to record their symptoms on a portable device for this purpose and to perform the study procedures required at each follow-up visit. The exclusion criteria were exacerbation during the four weeks prior to V0, the presence of concomitant respiratory disease (such as alpha-1 antitrypsin deficiency or diffuse bronchiectasis) or participation in any other research study or in a respiratory rehabilitation programme.

\section{Study Objectives}

The main objective of this study was to determine the differences in symptoms measured by the mean weekly E-RS scores at the end of the study (V2 \pm 3 days) between patients controlled or non controlled at V1.

The secondary study objectives were to compare the European Quality of Life 5 dimension (EQ5D-5L) scores between the controlled and uncontrolled patients and to examine differences in the E-RS subscales (Breathlessness, Chest symptoms and Cough \& Sputum) between the same groups of patients at V2.

\section{Study Variables}

Anthropometric data, details of comorbidities and COPD characteristics were obtained for each study participant as well as BODE, BODEx and COTE (COPD comorbidity) indexes. All participants had a spirometry at $\mathrm{V} 0$ with bronchodilator test, after inhaling 400 mcgr of salbutamol, in accordance with national and international guidelines. ${ }^{19,20}$

The patient's HRQoL was assessed by EQ5D-5L at V0 and V2. ${ }^{21}$ This questionnaire was filled by the patients in a printed version. The EQ5D-5L is a generic HRQoL questionnaire consisting of five domains (mobility, selfcare, usual activities, pain/discomfort and anxiety/depression) each with five possible responses, producing scores ranging from 0 to 1 (the higher the score, the better the quality of life). It has been extensively studied in costeffectiveness studies in the field of COPD. ${ }^{22}$

At each visit, the patient was instructed to complete PROs questionnaires, such as the COPD Assessment Test $\mathrm{CAT}^{23}$ CAT is a PRO that reports patient symptoms using 8 questions which can be answered in a Likert scale ranging from 0 (low symptom burden) to 40 (worse symptom burden). In addition, each patient recorded their respiratory symptoms every day, using a portable device and reporting the outcomes using the E-RS ${ }^{\circledR}$ questionnaire (EXACTC 2013, Evidera Inc., Bethesda, USA), which uses 11 
Table I Criteria for Clinical Control Based on Clinical Criteria or CAT Criteria

\begin{tabular}{|c|c|c|c|c|c|c|c|}
\hline \multicolumn{4}{|c|}{ Clinical Criteria for Control } & \multicolumn{4}{|c|}{ CAT Criteria for Control } \\
\hline Concept & Item & FEVI $\geq \mathbf{5 0} \%$ & FEV I $<50 \%$ & Concept & Item & FEVI $\geq \mathbf{5 0} \%$ & FEv $\mid<50 \%$ \\
\hline \multirow{4}{*}{$\begin{array}{l}\text { Low Impact } \\
\text { (at least } 3 \text { of the } 4 \text { ) }\end{array}$} & Dyspnea & $0-1$ & $0-2$ & Low impact & CAT & $0-10$ & $0-16$ \\
\hline & Rescue med & \multicolumn{2}{|c|}{$\leq 3$ times/week } & $\begin{array}{l}\text { Stability } \\
\text { ( } 3 \text { mo } \\
\text { follow up) }\end{array}$ & $\begin{array}{l}\text { Changes in } \\
\text { CAT }\end{array}$ & \multicolumn{2}{|l|}{$\leq 2$ points } \\
\hline & Sputum & \multicolumn{2}{|l|}{ White } & Control & & \multicolumn{2}{|c|}{ Low impact+ Stability } \\
\hline & Physical Activity & \multicolumn{2}{|c|}{$\geq 30$ minutes $/ \mathrm{d}$} & & & & \\
\hline \multirow{2}{*}{$\begin{array}{l}\text { Stability } \\
\text { (Both needed at } 3 \\
\text { mo) }\end{array}$} & Exacerbations & \multicolumn{2}{|l|}{ None } & & & & \\
\hline & $\begin{array}{l}\text { Subjective } \\
\text { perception }\end{array}$ & \multicolumn{2}{|l|}{ Same/Better } & & & & \\
\hline Clinical Control & & \multicolumn{2}{|c|}{ Low impact + Stability } & & & & \\
\hline
\end{tabular}

questions to establish a symptom score. The 11 items on the E-RS capture the severity of the cardinal respiratory symptoms of COPD, including breathlessness, cough, sputum, chest congestion, and chest tightness. The RS-Total score quantifies respiratory symptom severity. The 3 subscales embedded in the measure include RS-Breathlessness, RSCough \& Sputum, and RS-Chest Symptoms. The E-RS produces a total E-RS score (scores ranging from 0 to 40 , with higher values indicating greater severity of respiratory symptoms). The E-RS subscales produce scores from 0 to 17 (RS-Breathlessness), 0 to 11 (RS- Cough \& Sputum) and 0 to 12 (RS- Chest Symptoms). ${ }^{8}$

At V1 and V2, the patients were classified as controlled or uncontrolled, according to CAT and clinical criteria, ${ }^{12}$

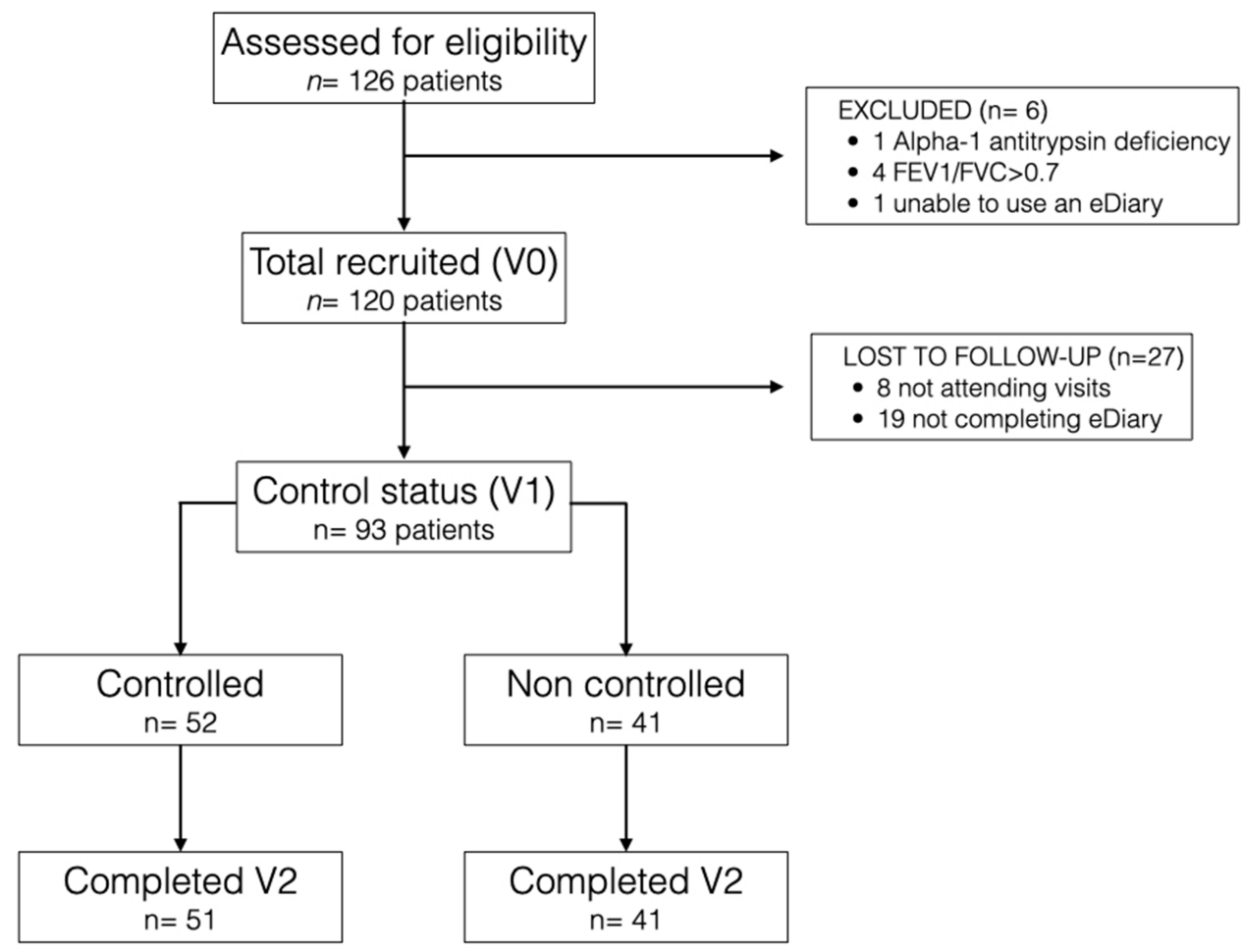

Figure I STROBE (STrengthening the Reporting of OBservational studies in Epidemiology) diagram of study participants. ${ }^{24}$ 
Table 2 Baseline Clinical Characteristics of Participants at VI

\begin{tabular}{|c|c|c|c|c|c|c|c|}
\hline & \multirow{2}{*}{$\begin{array}{l}\text { Total } \\
(n=93)\end{array}$} & \multicolumn{2}{|c|}{ Clinical Criteria } & \multirow[t]{2}{*}{ p-value } & \multicolumn{2}{|c|}{ CAT Criteria } & \multirow[t]{2}{*}{ p-value } \\
\hline & & Controlled & $\begin{array}{l}\text { Not } \\
\text { controlled }\end{array}$ & & Controlled & $\begin{array}{l}\text { Not } \\
\text { controlled }\end{array}$ & \\
\hline Age & $65.9 \pm 8.4$ & $64.9 \pm 8.1$ & $66.3 \pm 8.5$ & 0.410 & $64.2 \pm 6.7$ & $67.0 \pm 9.5$ & 0.111 \\
\hline Sex (M), n (\%) & 79 (84.9\%) & $46(88.0 \%)$ & $33(75.9 \%)$ & 0.274 & $38(86.4 \%)$ & $39(83.0 \%)$ & 0.655 \\
\hline \multicolumn{8}{|l|}{ Smoking history } \\
\hline Current smokers, n (\%) & $22(23.7 \%)$ & $14(28.0 \%)$ & $8(20.5 \%)$ & 0.417 & $13(25.9 \%)$ & $9(19.1 \%)$ & 0.247 \\
\hline Tobacco consumption, pack-years & $52.8 \pm 31.2$ & $45.9 \pm 21.3$ & $59.9 \pm 41.1$ & 0.054 & $55.4 \pm 34.7$ & $50.4 \pm 28.4$ & 0.451 \\
\hline FEVI, \% predicted & $49.8 \pm 16.5$ & $51.6 \pm 16.5$ & $48.8 \pm 16.5$ & 0.426 & $49.5 \pm 16.7$ & $50.5 \pm 16.7$ & 0.774 \\
\hline $\begin{array}{l}\text { Mod and Severe exacerbations, } \\
\text { prev year }\end{array}$ & $0.9 \pm 1.1$ & $0.6 \pm 1.1$ & $1.0 \pm 0.9$ & 0.120 & $0.5 \pm 0.8$ & $1.1 \pm 1.2$ & 0.005 \\
\hline Dyspnea, $\mathrm{mMRC} \geq 2$ & $49(52.8 \%)$ & $19(34 \%)$ & $30(74.4 \%)$ & 0.001 & $17(37.6 \%)$ & $30(63.8 \%)$ & 0.037 \\
\hline 6MWT & $427.6 \pm 108.4$ & $444.5 \pm 94.2$ & $415.8 \pm 122.3$ & 0.233 & $453.0 \pm 105.8$ & $405.2 \pm 107.7$ & 0.043 \\
\hline \multicolumn{8}{|l|}{ GOLD grade, $n(\%)$} \\
\hline GOLD A & $37(39.8 \%)$ & $28(58 \%)$ & $9(22 \%)$ & 0.008 & $29(65 \%)$ & $8(17 \%)$ & $<0.001$ \\
\hline GOLD B & $24(25.8 \%)$ & $12(24 \%)$ & $12(30 \%)$ & & $6(13 \%)$ & 18 (38\%) & \\
\hline GOLD C & $\mathrm{II}(\mathrm{II} .8 \%)$ & $4(6 \%)$ & $7(17 \%)$ & & $8(18 \%)$ & $3(6 \%)$ & \\
\hline GOLD D & $21(22.6 \%)$ & $8(12 \%)$ & $13(32 \%)$ & & $2(4 \%)$ & $19(39 \%)$ & \\
\hline \multicolumn{8}{|l|}{ COPD phenotype, $\mathrm{n}(\%)$} \\
\hline Non exacerbator & $49(52.7 \%)$ & $32(64 \%)$ & $17(43 \%)$ & 0.047 & $29(66 \%)$ & $20(42 \%)$ & 0.025 \\
\hline $\mathrm{ACO}$ & $13(14.0 \%)$ & $8(16 \%)$ & $5(11 \%)$ & & $7(16 \%$ & $6(14 \%)$ & \\
\hline Frequent exacerbator with $\mathrm{CB}$ & $20(21.5 \%)$ & $2(4 \%)$ & $7(18 \%)$ & & I (2\%) & $9(19 \%)$ & \\
\hline Frequent exacerbator with emphysema & II (II.8\%) & $8(16 \%)$ & II (28\%) & & $7(16 \%)$ & $12(25 \%)$ & \\
\hline COTE index & $0.9 \pm 1.6$ & $0.8 \pm 1.6$ & $1.1 \pm 1.7$ & 0.374 & $0.7 \pm 1.1$ & $1.1 \pm 1.9$ & 0.256 \\
\hline COTE index $>4$ points, $n(\%)$ & $7(7.6 \%)$ & $3(6.0 \%)$ & $4(10.3 \%)$ & 0.223 & $3(6.8 \%)$ & $4(8.5 \%)$ & 0.306 \\
\hline \multicolumn{8}{|l|}{ Symptom burden } \\
\hline CAT score & $11.0 \pm 6.7$ & $9.1 \pm 6.7$ & $13.0 \pm 6.7$ & 0.007 & $6.7 \pm 3.4$ & $14.8 \pm 6.4$ & $<0.001$ \\
\hline
\end{tabular}

Abbreviations: FEVI, forced expiratory volume at Ist second; mMRC, modified Medical Research Council; 6MWT, 6 minutes walking test; ACO, asthma; COPD, overlap; COTE, comorbidities index; CAT, COPD assessment test; CCQ, Clinical COPD questionnaire.

Table 3 Impact, Stability and Control During Study Visits (VI and V2) Among Study Participants According to Clinical or CAT Criteria

\begin{tabular}{|l|l|l|l|l|l|}
\hline CAT Evaluation & V I & V2 & Clinical Evaluation & V I & V2 \\
\hline $\begin{array}{l}\text { Impact (CAT) } \\
\text { Low }\end{array}$ & $60(64.4 \%)$ & $57(61.3 \%)$ & Clinical Impact & $62(66.7 \%)$ & $68(73.1 \%)$ \\
High & $33(35.5 \%)$ & $36(38.8 \%)$ & High & $31(33.4 \%)$ & $25(26.9 \%)$ \\
\hline $\begin{array}{l}\text { Stability (CAT) } \\
\text { Stable }\end{array}$ & $73(78.5 \%)$ & $68(73.1 \%)$ & Stable & & \\
No & $20(21.6 \%)$ & $25(26.9 \%)$ & No & $25(26.9 \%)$ & $27(29.1 \%)$ \\
\hline $\begin{array}{l}\text { Control (CAT) } \\
\text { Controlled }\end{array}$ & $45(48.4 \%)$ & $50(53.8 \%)$ & Controlled & & $52(55.1 \%)$ \\
Not controlled & $48(51.6 \%)$ & $43(46.2 \%)$ & Not controlled & $41(44.1 \%)$ & $38(59.2 \%)$ \\
\hline
\end{tabular}

as defined in Table 1. Investigators were not aware about the control status, and clinical decisions were made as usual care.

\section{Statistical Analysis}

The study data are presented as mean (SD) for the continuous variables and as $\mathrm{n}(\%$ of total) for the ordinal 
Table 4 Changes in Control Status Among Study Participants Between VI and V2, Either by CAT Criteria or Clinical Criteria

\begin{tabular}{|l|l|l|}
\hline & $\begin{array}{l}\text { CAT } \\
\text { Criteria }\end{array}$ & $\begin{array}{l}\text { Clinical } \\
\text { Criteria }\end{array}$ \\
\hline Persistent controlled & $34(38.6 \%)$ & $4 I(44.8 \%)$ \\
Persistent non- controlled & $29(31.3 \%)$ & $29(31.3 \%)$ \\
Achieving control from VI to V2 & $21(21.7 \% \%)$ & $14(15.4 \%)$ \\
Losing control from VI to V2 & $9(8.4 \%)$ & $9(8.5 \%)$ \\
\hline
\end{tabular}

variables. Normal distribution of variables was tested using the Kolmogorov-Smirnov test. Normally distributed continuous variables were compared by Student's $t$-test of by ANOVA. For non-normal continuous variables, the Mann-Whitney U non-parametric test or the KruskalWallis non-parametric test were used. Ordinal variables were compared by the chi-square test. E-RS measures were compared between controlled and uncontrolled patients using a general linear model for repeated measures, and the estimated marginal means were calculated. All statistical analyses were performed using the SPSS statistical package version 24.0.0.0 (IBM, Armonk, NY, USA). A value of $\mathrm{p}<0.05$ was considered significant.

\section{Results}

From June 2017 to October 2018, 126 patients at 15 hospitals throughout Spain were invited to participate in this study. Of these, 120 completed V0 and were recruited. However, 27 participants were lost to follow up, leaving a final study population of 93 patients. Figure 1 shows the STROBE diagram for the selection of participants.

Table 2 shows the characteristics of the study population, comparing controlled vs uncontrolled patients at V1, by clinical criteria and by CAT. The majority of the study participants $(84.9 \%)$ were male, with a mean age of 65.9 years (SD 8.4) and $23.7 \%$ were active smokers. The mean $\mathrm{FEV}_{1}$ was $49.8 \%$ (SD 16.5\%) predicted. The most frequent GOLD group was A and the comorbidity load was low according to the COTE index. In general, differences were observed between controlled and uncontrolled patients in clinical phenotype, GOLD classification and dyspnea, and in their CAT scores.

Table 3 shows the impact, stability and control achieved at V1 and V2, according to clinical criteria and CAT. At V1, 48\% and $55 \%$ of patients were controlled, according to CAT and clinical criteria, respectively. During the study, the proportion of patients who achieved clinical control increased to $53 \%$ according to CAT and to $59 \%$, according to clinical criteria. During follow-up, more than a third of the patients remained controlled, a third remained uncontrolled, and $8 \%$ changed from controlled to uncontrolled and between $15 \%$ and $21 \%$ changed from uncontrolled to controlled, according to clinical criteria or CAT, respectively. (Table 4).

Figure 2 shows the E-RS scores at $\mathrm{V} 2$ between controlled and non-controlled patients, either by CAT or clinical criteria. Controlled patients had statistically significant lower E-RS scores at V2 than non-controlled patients regardless criteria
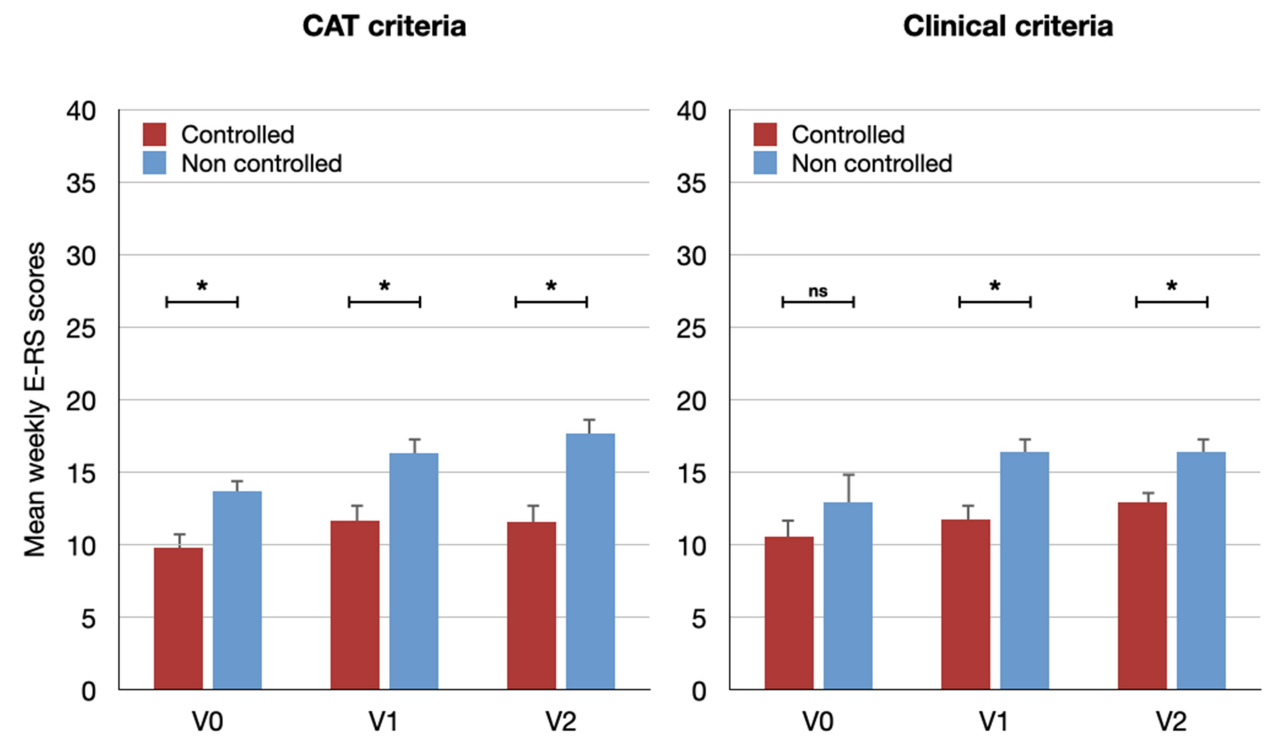

Figure 2 Mean (SE) values of E-RS scores among patients controlled and not controlled (by CAT criteria-left- or by clinical criteria-right) at study visits. * ${ }^{*}<0.05$. 
CAT criteria

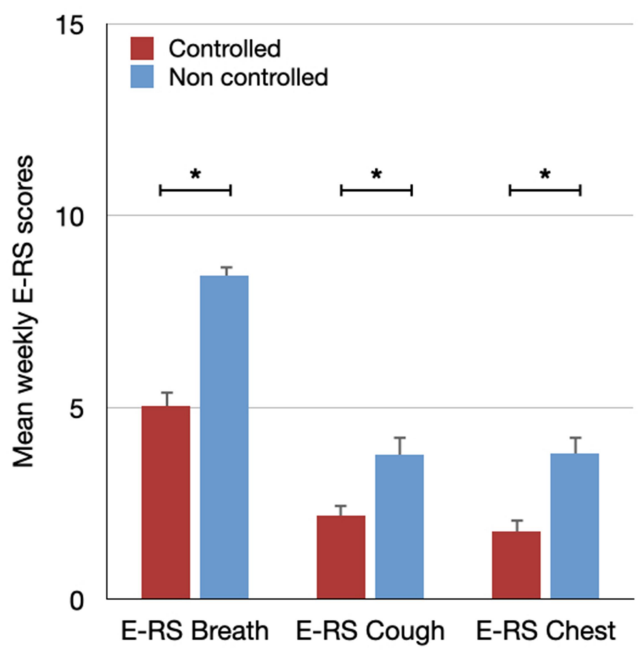

Clinical criteria

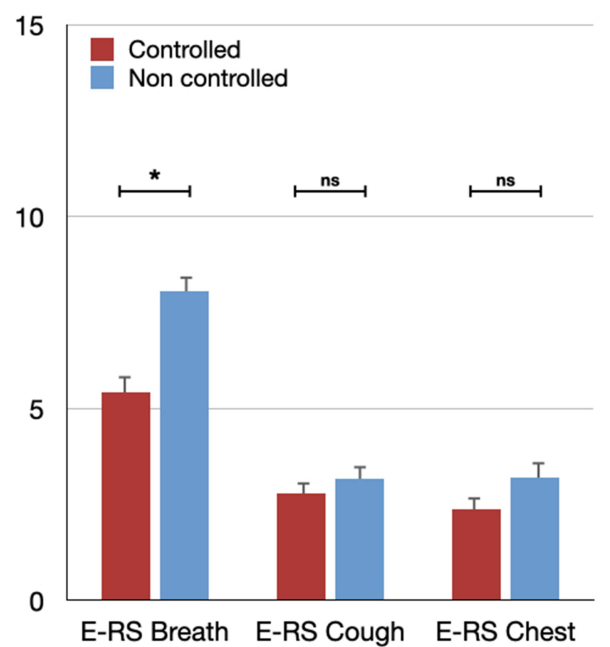

Figure 3 Mean (SE) weekly values of E-RS sub-scales scores (E-RS breath, E-RS cough and E-RS chest) at Visit 2 among controlled and not controlled patients (either by CAT criteria- left- or by clinical criteria-right). ${ }^{*} \mathrm{p}<0.05$.

for control. E-RS scores showed also significant differences between controlled and non-controlled patients at V1.

The results obtained for the E-RS subscales at V2 are shown in Figure 3. In this respect, there were statistically significant differences between controlled and uncontrolled patients in the three subscales, according to CAT. In terms of clinical criteria, statistically significant differences were only observed for the E-RS Breath subscale but not for Cough and Chest symptoms domains.

Tables 5 and 6 reflect the outcomes achieved with respect to E-RS scores and subscales among the study visits either by clinical or CAT criteria. In summary, the E-RS total scores at V1 and V2 for the controlled patients were significantly better from those achieved by the uncontrolled patients, both by clinical criteria and by CAT.
Figure 4 shows the HRQoL results obtained by EQ5D, both by CAT and by clinical criteria. In both cases, there were statistically significant differences between controlled and uncontrolled patients at V2. Full EQ5D results for controlled and non-controlled patients in males and females can be found at tables $\mathrm{S} 2$ and $\underline{\mathrm{S} 3}$.

\section{Discussion}

The study results show that the controlled patients, either by CAT or by clinical criteria, recorded a lower symptom load on the E-RS symptom diary than uncontrolled patients, over a six-month follow-up. Furthermore, the controlled patients had a better HRQoL throughout this period. These results corroborate previous studies that have highlighted the value of the clinical control concept

Table 5 Mean Weekly E-RS Scores at V0, VI and V2 Among Controlled and Not Controlled Patients at VI by CAT Criteria

\begin{tabular}{|c|c|c|c|c|c|c|c|}
\hline & & vo & $P$ value & VI & $P$ value & V2 & $P$ value \\
\hline E-RS total score & $\begin{array}{l}\text { Controlled } \\
\text { Not controlled }\end{array}$ & $\begin{array}{l}9.5 \pm 4.3 \\
\mid 4.1 \pm 4.6\end{array}$ & $<0.001$ & $\begin{array}{l}11.2 \pm 6.2 \\
16.8 \pm 5.2\end{array}$ & $<0.001$ & $\begin{array}{l}11.6 \pm 6.2 \\
17.8 \pm 6.2\end{array}$ & $<0.001$ \\
\hline E-RS Breath & $\begin{array}{l}\text { Controlled } \\
\text { Not controlled }\end{array}$ & $\begin{array}{l}3.0 \pm 3.3 \\
5.8 \pm 3.2\end{array}$ & $<0.001$ & $\begin{array}{l}4.4 \pm 3.5 \\
8.2 \pm 3.7\end{array}$ & $<0.001$ & $\begin{array}{l}4.7 \pm 2.9 \\
8.6 \pm 4.5\end{array}$ & $<0.001$ \\
\hline E-RS Cough & $\begin{array}{l}\text { Controlled } \\
\text { Not controlled }\end{array}$ & $\begin{array}{l}2.0 \pm 2.0 \\
3.8 \pm 2.2\end{array}$ & $<0.001$ & $\begin{array}{l}2.0 \pm 1.8 \\
3.6 \pm 2.3\end{array}$ & 0.001 & $\begin{array}{l}2.1 \pm 1.5 \\
3.7 \pm 2.1\end{array}$ & $<0.001$ \\
\hline E-RS Chest & $\begin{array}{l}\text { Controlled } \\
\text { Not controlled }\end{array}$ & $\begin{array}{l}0.9 \pm 1.5 \\
2.2 \pm 2.1\end{array}$ & 0.001 & $\begin{array}{l}1.7 \pm 2.1 \\
3.3 \pm 2.3\end{array}$ & 0.001 & $\begin{array}{l}1.7 \pm 2.0 \\
3.9 \pm 2.5\end{array}$ & $<0.001$ \\
\hline
\end{tabular}

Notes: $\mathrm{P}$ values are referred to $\mathrm{T}$ test between controlled and not controlled patients at each visit. 
Table 6 Mean Weekly E-RS Scores at V0, VI and V2 Among Controlled and Not Controlled Patients at VI by Clinical Criteria

\begin{tabular}{|l|l|l|l|l|l|l|l|}
\hline & & V0 & P value & VI & P value & V2 & P value \\
\hline E-RS total score & $\begin{array}{l}\text { Controlled } \\
\text { Not controlled }\end{array}$ & $\begin{array}{l}10.2 \pm 4.5 \\
13.6 \pm 4.8\end{array}$ & 0.001 & $\begin{array}{l}11.3 \pm 5.5 \\
16.9 \pm 5.2\end{array}$ & $<0.001$ & $\begin{array}{l}12.5 \pm 5.5 \\
17.5 \pm 7.0\end{array}$ & $<0.001$ \\
\hline E-RS Breath & Controlled & $3.6 \pm 3.1$ & 0.015 & $4.8 \pm 3.7$ & $<0.001$ & $5.3 \pm 3.1$ \\
& Not controlled & $5.4 \pm 3.8$ & & $8.4 \pm 3.6$ & & $<.7 \pm 4.8$ \\
\hline E-RS Cough & Controlled & $2.4 \pm 2.1$ & 0.041 & $2.1 \pm 1.8$ & 0.001 & $2.6 \pm 1.5$ \\
& Not controlled & $3.4 \pm 2.4$ & & $3.6 \pm 2.2$ & & $3.4 \pm 2.4$ & 0.069 \\
\hline E-RS Chest & Controlled & $1.2 \pm 1.7$ & 0.205 & $2.0 \pm 2.3$ & 0.024 & $2.3 \pm 2.3$ & 0.16 \\
& Not controlled & $1.7 \pm 2.1$ & & $3.1 \pm 2.2$ & & $3.7 \pm 2.8$ \\
\hline
\end{tabular}

Notes: $P$ values are referred to $T$ test between controlled and not controlled patients at each visit.

as a means of evaluating and monitoring patients with COPD. ${ }^{11-16}$

The E-RS questionnaire is a validated clinical instrument that has been used as an outcomes measure in intervention studies (pharmacological or otherwise), detailing the respiratory symptoms of patients with COPD and their evolution over time. ${ }^{8,25-27}$ Since it is based on a symptom 's diary reported by the patient (reflecting daily variations), the data interpretation is more robust than that of visit questionnaires such as CAT or CCQ (but lacks widespread use because it is designed for research porpoises). The clinically important minimum difference is defined as two units on the E-RS scale, ${ }^{8}$ a difference that was exceeded between controlled and uncontrolled patients throughout the study. Furthermore, there were differences between controlled and uncontrolled patients for each of the subscales, especially those of Breathlessness. These differences were of a similar magnitude when patients were classified as controlled or uncontrolled according to either CAT or clinical criteria.

The EQ5D is a generic HRQoL questionnaire that has been validated for the analysis of general quality of life in patients with COPD. Our results showed that controlled patients had a better HRQoL than those whose condition was uncontrolled. Moreover, the HRQoL values obtained were higher than those reported in previous studies of patients with COPD in Spain, ${ }^{28}$ revealing better HRQoL in our population (probably due to a less severe disease).

Our findings regarding the proportion of controlled and uncontrolled patients are similar to those obtained in previous studies, ${ }^{12,15}$ with around $50 \%$ of patients achieving clinical control, whether assessed by clinical criteria or by
CAT criteria

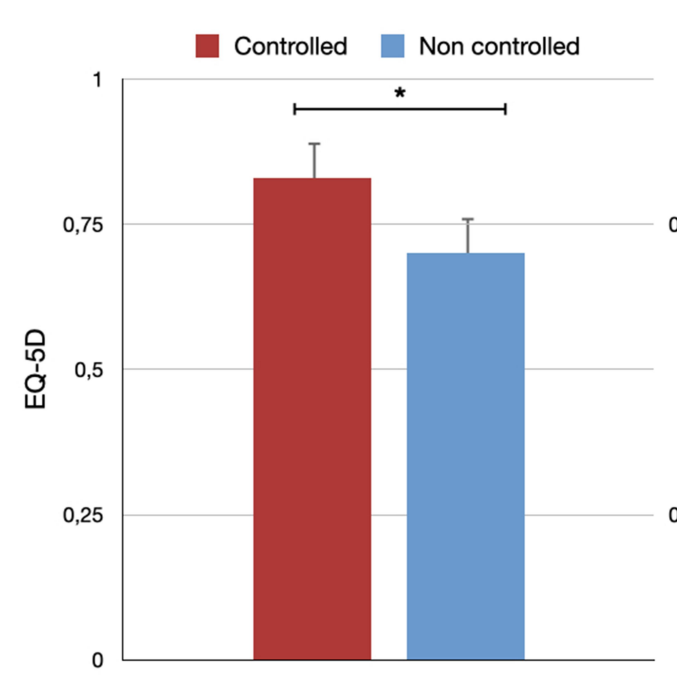

Clinical criteria

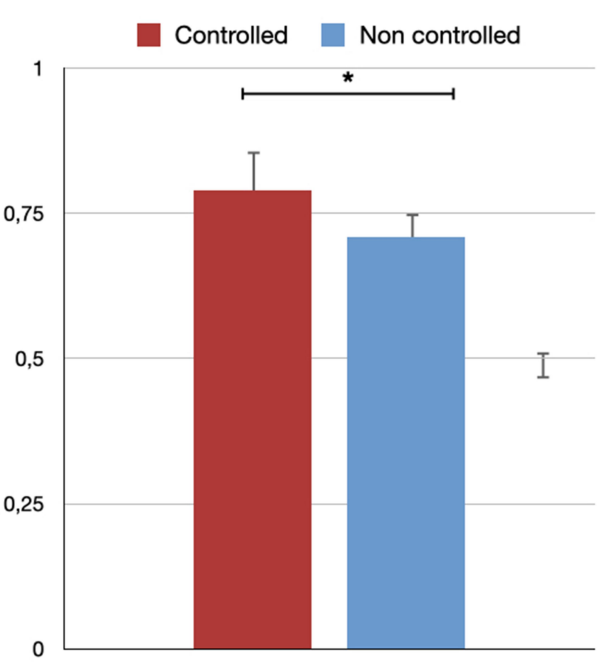

Figure 4 Mean EQ5D values at V2 between controlled and not controlled patients at V2 according to CAT criteria (left) and clinical criteria (right). ${ }^{*} \mathrm{p}<0.05$. 
the CAT score, with clinical criteria being more accurate than CAT to identify controlled patients (which could be explained by a more precise capture of COPD symptoms by clinical criteria). As previously demonstrated, this indicator is sensitive to changes in the patient's condition, with over $20 \%$ of patients presenting changes in control status during a 3-months follow-up period. ${ }^{15}$ Previous studies have shown that these changes in control status are more sensitive to changes in the clinical status of COPD than changes in phenotype, level of risk of GOLD groups A-D; ${ }^{15}$ and, furthermore, this changes in control status are associated with the risk of future exacerbations. ${ }^{16,29}$ Our results extend these observations by demonstrating that the control status is associated with the symptom burden and the HRQoL of patients with COPD. Taken together, these evidences suggest that the control status could be a valid tool for assessing effectiveness of treatment in routine clinical practice and guide changes in treatment during follow-up.

This study presents various strengths, including its multicentre design, the use of a validated tool for recording respiratory symptoms in patients with COPD and the consistency between the results obtained and those previously reported from other studies analysing different aspects of the concept of control. On the other hand, there are also certain limitations, such as the low proportion of females (which is in line with other studies performed in Spain), ${ }^{7,15}$ the inclusion of patients attending to routine visits, the risk of selecting patients more prone to the use of technology and the loss of patients during the follow-up period (although this was to be expected in a study of this nature), the selection exclusively of patients seen at pulmonology consultations (which could have decreased the proportion of controlled patients), and the lack of data on the baseline medical treatment, due to limitations in this respect imposed by the administrative authorities during registration of the study. Another limitation is intrinsic to the COPD control concept, which is the inclusion of variables such as dyspnea that could impact CAT or EQ5D questionnaires.

In conclusion, clinical control, whether determined by clinical criteria or by CAT, is associated with a lower symptom load and a better HRQoL. These results, together with those obtained in previous studies about different aspects of the control tool, support the use of the control in clinical practice at any healthcare level.

\section{Abbreviations}

CAT, COPD Assessment Test; CCQ, clinical COPD questionnaire; $\mathrm{COPD}$, chronic obstructive pulmonary disease; E-RS, EXACT Respiratory Symptoms; EQ5D, European Quality of Life 5 Dimensions questionnaire; $\mathrm{FEV}_{1}$, forced expiratory volume in the first second; FVC, forced vital capacity; GOLD, Global Initiative for Chronic Obstructive Lung Disease; HRQoL, health-related quality of life; PRO, patient reported outcomes.

\section{Data Sharing Statement}

The datasets used and/or analysed during the current study are available from the corresponding author on reasonable request.

\section{Ethical Approval and Consent to Participate}

This study was designed in accordance with the principles of the Declaration of Helsinki and carried out in accordance with the protocol and with the norms of good clinical practice. It was submitted to the appropriate Clinical Research Ethics Committee (CEI Granada, Code 0458-N-16) for evaluation, and the Spanish Agency for Medicines and Health Products (AEMPS) was notified. All participants gave their written informed consent to take part in the study.

\section{Acknowledgements}

We would like to acknowledge Salvador López Agustina and all the people from CrossData CRO, for their priceless support during the study E-RS ${ }^{\circledR}$ is a registered trademark of Evidera Inc. The authors used this questionnaire.

\section{Author Contributions}

All authors made a significant contribution to the work reported, whether that is in the conception, study design, execution, acquisition of data, analysis and interpretation, or in all these areas; took part in drafting, revising or critically reviewing the article; gave final approval of the version to be published; have agreed on the journal to which the article has been submitted; and agree to be accountable for all aspects of the work.

\section{Funding}

This study was funded by an unrestricted grant from Novartis Spain. This company did not intervene in the development of the study, data collection, analysis of results or drafting of the manuscript. 


\section{Disclosure}

Dr. Alcázar-Navarrete reports grants, non-financial support and personal fees from GSK, grants, personal fees and non-financial support from Novartis AG, personal fees and non-financial support from Boehringer Ingelheim, personal fees and non-financial support from Chiesi, grants, personal fees and non-financial support from Laboratorios Menarini, personal fees from Gebro, personal fees and non-financial support from Astra-Zeneca, personal fees from Laboratorios Rovi, personal fees from Laboratorios Ferrer, grants, personal fees, non-financial support from Menarini, outside the submitted work.

Dra. Fuster has nothing to disclose.

Dra García-Sidro reports personal fees from GSK, Pfizer, Novartis AG, Menarini, Boehringer Ingelheim, Astra-Zeneca, Gebro and Laboratorios Rovi, outside the submitted work.

Dr. García Rivero has nothing to disclose.

Dr. Abascal-Bolado has nothing to disclose.

Dr. Pallarés-Sanmartín has received lecture fees, consultancy fees and/or support for conference attendance from various pharmaceutical companies such as Novartis, GlaxoSmithKline, Chiesi, Boehringer Ingelheim, Mundipharma, Menarini, Laboratorios Esteve, Astra Zeneca, Teva Pharmaceutical, Ferrer, Rovi, Bial, Faes Farma, ALK Abelló and Gebro Pharma outside the submitted work.

Dr. Marquez- Martín has nothing to disclose.

Dr. Valido Morales has received lecture fees, consultancy fees and/or support for conference attendance from various pharmaceutical companies, such as GlaxoSmithKline, Chiesi, Boehringer Ingelheim, Menarini, Pfizer, Novartis, Laboratorios Esteve, Teva Pharmaceutical, Ferrer, Rovi, Astra Zeneca, Bial, Grifols, Faes Farma and Gebro Pharma, outside the submitted work.

Dr. Callejas González has received lecture fees, consultancy fees and/or support for conference attendance from various pharmaceutical companies, such as GlaxoSmithKline, Chiesi, Boehringer Ingelheim, Mundipharma, Menarini, Pfizer, Novartis, Laboratorios Esteve, Teva Pharmaceutical, Ferrer, Rovi, Roche, Astra Zeneca, Bial, Actelion, Grifols, CSL Behring, Faes Farma and Gebro Pharma, and reports personal fees from GlaxoSmithKline, personal fees from Chiesi, personal fees from Boehringer Ingelheim, personal fees from Mundipharma, personal fees from Menarini, personal fees from Pfizer, personal fees from Novartis, personal fees from Laboratorios Esteve, personal fees from Teva Pharmaceutical, personal fees from Ferrer, personal fees from Rovi, personal fees from Roche, personal fees from Astra Zeneca, personal fees from Bial, personal fees from Actelion, personal fees from Grifols, personal fees from CSL Behring, personal fees from Faes Farma, personal fees from Gebro Pharma, outside the submitted work.

Dra. Palop reports personal fees from Astra Zeneca, GlaxoSmithKline, Chiesi, Boehringer -Ingelheim, Novartis, Teva, Menarini, Rovi, outside the submitted work.

Dr. JA Riesco reports grants and personal fees from GSK, grants, personal fees and non-financial support from Pfizer, Novartis AG, Menarini, personal fees and non-financial support from Boehringer Ingelheim, personal fees and non-financial from Astra-Zeneca, Grants and personal fees from Gebro, personal fees from Laboratorios Rovi, outside the submitted work.

Dr. Golpe reports personal fees from AstraZeneca, Boehringer Ingelheim, Chiesi, Menarini, Rovi, Zambon, Grifols, Novartis, Ferrer, Gebro Pharma, Laboratorios Esteve and GlaxoSmithKline, outside the submitted work.

Dr. Soler-Cataluña reports speaking fees from Laboratorio Esteve, Mundipharma, grants, personal fees, speaking fees from AstraZeneca, grants, personal fees, non-financial support from Boehringer Ingelheim, personal fees from Bial, personal fees from Ferrer, personal fees, non-financial support from Menarini, personal fees, nonfinancial support from Novartis, personal fees from Rovi and Teva; consulting fees from AirLiquide, AstraZeneca, Boehringer Ingelheim, GlaxoSmithKline, Laboratorios Esteve, Mundipharma grants, personal fees from Chiesi, personal fees from Ferrer, grants, personal fees from; research grants from GlaxoSmithKline and Boehringer Ingelheim, outside the submitted work.

Marc Miravitlles has received speaker fees from AstraZeneca, Boehringer Ingelheim, Chiesi, Cipla, Menarini, Rovi, Bial, Sandoz, Zambon, CSL Behring, Grifols and Novartis, consulting fees from AstraZeneca, Boehringer Ingelheim, Chiesi, GlaxoSmithKline, Bial, Gebro Pharma, Kamada, CSL Behring, Laboratorios Esteve, Ferrer, Mereo Biopharma, Verona Pharma, TEVA, Spin Therapeutics, pH Pharma, Novartis, Sanofi and Grifols and research grants from GlaxoSmithKline and Grifols; reports personal fees from AstraZeneca, Boehringer Ingelheim, Chiesi, Cipla, Menarini, Rovi, 
Bial, Sandoz, Zambon, CSL Behring, Grifols and Novartis, personal fees from AstraZeneca, Boehringer Ingelheim, Chiesi, GlaxoSmithKline, Bial, Gebro Pharma, Kamada, CSL Behring, Laboratorios Esteve, Ferrer, Mereo Biopharma, Verona Pharma, TEVA, Spin Therapeutics, pH Pharma, Novartis, Sanofi and Grifols, grants from GlaxoSmithKline and Grifols., outside the submitted work.

The authors report no other potential conflicts of interest for this work.

\section{References}

1. Miravitlles M, Soriano JB, García-Río F, et al. Prevalence of COPD in Spain: impact of undiagnosed COPD on quality of life and daily life activities. Thorax. 2009;64:863-868. doi:10.1136/thx.2009.115725

2. Kassebaum NJ, Arora M, Barber RM, et al. Global, regional, and national disability-adjusted life-years (DALYs) for 315 diseases and injuries and healthy life expectancy (HALE), 19902015: a systematic analysis for the global burden of disease study 2015. Lancet. 2016;388:1603-1658.

3. Anzueto A, Miravitlles M. Pathophysiology of dyspnea in COPD. Postgrad Med. 2017;129:366-374. doi:10.1080/00325481.2017.1301190

4. Hanania NA, O'Donnell DE. Activity-related dyspnea in chronic obstructive pulmonary disease: physical and psychological consequences, unmet needs, and future directions. Int $J$ Chron Obstruct Pulmon Dis. 2019;14:1127-1138. doi:10.2147/COPD.S188141

5. Nishimura K, Izumi T, Tsukino M, Oga T. Dyspnea Is a better predictor of 5-year survival than airway obstruction in patients with COPD. Chest. 2002;121:1434-1440. doi:10.1378/chest.121.5.1434

6. Kessler R, Partridge MR, Miravitlles M, et al. Symptom variability in patients with severe COPD: a pan-European cross-sectional study. Eur Respir J. 2011;37:264-272. doi:10.1183/09031936.00051110

7. Espinosa de Los Monteros MJ, Peña C, Soto HEJ, Jareño J, Miravitlles M. Variability of respiratory symptoms in severe COPD. Arch Bronconeumol. 2012;48:3-7. doi:10.1016/j.arbres.2011.07.004

8. Leidy NK, Murray LT, Monz BU, et al. Measuring respiratory symptoms of COPD: performance of the EXACT- Respiratory Symptoms Tool (E-RS) in three clinical trials. Respir Res. 2014;15:124. doi:10.1186/s12931-014-0124-z

9. Soler-Cataluña JJ, Alcázar-Navarrete B, Miravitlles M. The concept of control of COPD in clinical practice. Int J Chron Obstruct Pulmon Dis. 2014;9:1397-1405.

10. Soler-Cataluña JJ, Alcázar-Navarrete B, Miravitlles M. The concept of control in COPD: A new proposal for optimising therapy. Eur Respir J. 2014;44:1072-1075.

11. Nibber A, Chisholm A, Soler-Cataluña JJ, Alcazar B, Price D, Miravitlles M. Validating the concept of COPD control: a real-world cohort study from the United Kingdom. COPD J Chronic Obstr Pulm Dis. 2017;14:504-512. doi:10.1080/15412555.2017.1350154

12. Soler-Cataluña JJ, Marzo M, Catalan P, Miralles C, Alcazar B, Miravitlles M. Validation of clinical control in COPD as a new tool for optimizing treatment. Int $J$ Chron Obstruct Pulmon Dis. 2018;13:3719-3731. doi:10.2147/COPD.S178149

13. Soler-Cataluña JJ, Alcázar B, Miravitlles M. Clinical control in COPD: a new therapeutic objective? Arch Bronconeumol. 2020;56: 68-69. doi:10.1016/j.arbres.2019.06.004
14. Miravitlles M, Sliwinski P, Rhee CK, et al. Evaluation of criteria for clinical control in a prospective, international, multicenter study of patients with COPD. Respir Med. 2018;136:8-14. doi:10.1016/j. rmed.2018.01.019

15. Soler-Cataluna JJ, Alcazar B, Marzo M, et al. Validation of clinical control in COPD as a new tool for optimizing treatment. Chest. 2020;157:1138-1146.

16. Barrecheguren M, Kostikas K, Mezzi K, et al. COPD clinical control as a predictor of future exacerbations: concept validation in the SPARK study population. Thorax. 2020;75:351-353. doi:10.1136/ thoraxjnl-2018-212752

17. Grupo de Trabajo de GesEPOC. Guía de Práctica Clínica para el Diagnóstico y Tratamiento de Pacientes con Enfermedad Pulmonar Obstructiva Crónica (EPOC) - guía Española de la EPOC (GesEPOC). Versión 2017. Arch Bronconeumol. 2017;53(Suppl:1-64).

18. Vogelmeier CF, Criner GJ, Martínez FJ, et al. Global strategy for the diagnosis, management, and prevention of chronic obstructive lung disease 2017 report: GOLD executive summary. Arch Bronconeumol. 2017;53:128-149. doi:10.1016/j.arbres.2017.02.001

19. García-Río F, Calle M, Burgos F, et al. Espirometría. Arch Bronconeumol. 2013;49:388-401. doi:10.1016/j.arbres.2013.04.001

20. Miller MR. Standardisation of spirometry. Eur Respir J. 2005;26:319-338. doi:10.1183/09031936.05.00034805

21. Janssen MF, Pickard AS, Golicki D, et al. Measurement properties of the EQ-5D-5L compared to the EQ-5D-3L across eight patient groups: A multi-country study. Qual Life Res. 2013;22 (7):1717-1727. doi:10.1007/s11136-012-0322-4

22. Miravitlles M, Huerta A, Fernández-Villar JA, et al. Generic utilities in chronic obstructive pulmonary disease patients stratified according to different staging systems. Health Qual Life Outcomes. 2014;12:120. doi:10.1186/s12955-014-0120-5

23. Jones PW, Brusselle G, Dal Negro RW, et al. Properties of the COPD assessment test in a cross-sectional European study. Eur Respir J. 2011;38:29-35. doi:10.1183/09031936.00177210

24. von Elm E, Altman DG, Egger M, Pocock SJ, Gøtzsche PC, Vandenbroucke JP; STROBE Initiative. The Strengthening the Reporting of Observational Studies in Epidemiology (STROBE)statement: guidelines for reporting observational studies. Lancet. 2007 Oct 20;370(9596):1453-7. PMID: 18064739

25. Tabberer M, Lomas DA, Birk R, et al. Once-daily triple therapy in patients with COPD: patient-reported symptoms and quality of life. Adv Ther. 2018;35:56-71. doi:10.1007/s12325-017-0650-4

26. Nishimura K, Oga T, Nakayasu K, Ogasawara M, Hasegawa Y, Mitsuma S. How different are COPD-specific patient reported outcomes, health status, dyspnea and respiratory symptoms? An observational study in a working population. BMJ Open. 2019;9:e025132. doi:10.1136/bmjopen-2018-025132

27. Bowler R, Allinder M, Jacobson S, et al. Real-world use of rescue inhaler sensors, electronic symptom questionnaires and physical activity monitors in COPD. BMJ Open Respir Res. 2019;6:e00350. doi:10.1136/bmjresp-2018-000350

28. Esquinas C, Ramon MA, Nuñez A, et al. Correlation between disease severity factors and EQ-5D utilities in chronic obstructive pulmonary disease. Qual Life Res. 2020;29:607-617. doi:10.1007/s11136-01902340-4

29. Miravitlles M, Sliwinski P, Rhee CK, et al. Respiratory Effectiveness Group (REG). Predictive value of control of COPD for risk of exacerbations: an international, prospective study. Respirology. 2020. doi:10.1111/resp.13811 


\section{Publish your work in this journal}

The International Journal of COPD is an international, peer-reviewed journal of therapeutics and pharmacology focusing on concise rapid reporting of clinical studies and reviews in COPD. Special focus is given to the pathophysiological processes underlying the disease, intervention programs, patient focused education, and self management protocols. This journal is indexed on PubMed Central, MedLine and CAS. The manuscript management system is completely online and includes a very quick and fair peer-review system, which is all easy to use. Visit http://www.dovepress.com/testimonials.php to read real quotes from published authors. 